\title{
Study on removal of Se(IV) using Fe-Mn layered double hydroxides and Fe-Mn Dos (double oxides)
}

\author{
Enkhtur Otgonjargal ${ }^{1}$, Kitae Baek², Jung-Seok Yang ${ }^{3}$, Enkhtuul Surenjav ${ }^{1}$, \\ Aruukhan Dashkhuu Khasbaatar ${ }^{4 *}$ \\ ${ }^{1}$ Institute of Chemistry and Chemical Technology, Mongolian Academy of Sciences, \\ 4th Building of MAS, Ulaanbaatar 13330, Mongolia \\ ${ }^{2}$ Chonbuk National University, 567 Baekje-daero, Deokjin-gu, Jeongju, Jeollabukdo 570-752, Republic of Korea \\ ${ }^{3}$ KIST-Gangneung Institute, Gangneung, Gangwon 210-340, Republic of Korea \\ ${ }^{4}$ School of Engineering and Applied Sciences, National University of Mongolia, P.O.Box 46A/257, \\ 14201 Main building of NUM, University street 1, Sukhbaatar district, Ulaanbaatar, Mongolia \\ *Corresponding author: d_khasbaatar@seas.num.edu.mn; ORCID ID:0000-0002-1311-1506
}

Received: 17 October 2019; revised: 9 December 2019; accepted: 18 December 2019

\begin{abstract}
In this study, Fe-Mn- $\mathrm{CO}_{3}$ layered double hydroxide (LDHs) and Fe-Mn Double oxide (DOs) were synthesized by the corecipitation methods for Se(IV) removal from aqueous solutions. The Se(IV) adsorption capacities and removal mechanism of Fe-Mn LDH and Fe-Mn DOs determined by batch and column experiments. The calculated Se(IV) adsorption capacities on Fe-Mn LDH and Fe-Mn DOs were 52.5 and $55.3 \mathrm{mg} / \mathrm{g}$, respectively. Kinetic models applied to the adsorption of Se(IV) on the Fe-Mn LDH and Fe-Mn DOs calculated using pseudo-first, second-order, Elovich, and Intraparticle diffusion kinetic models and all kinetic parameters were calculated and discussed. Isotherm studies were also performed using Langmuir, Freundlich, Temkin, and Dubinin-Radushkevich equations in the temperature range of $283-323 \mathrm{~K}$. Adsorption kinetics and isotherm experiments are well fitted pseudo-second order model and Freundlich isotherm, respectively. The production of this adsorbent is cost-effective for industrial applications.
\end{abstract}

Keywords: Adsorption, double oxide, layered double hydroxide, selenium

\section{INTRODUCTION}

Selenium contamination occurs including mining operations, mineral processing abandoned mine sites, petroleum processing, and agricultural runoff, which are transported to fish, other aquatic life, and water birds [1, 2]. Naturally, selenium exists in the oxidation states of selenide $(\mathrm{Se}(-\mathrm{II}))$, elemental selenium $(\mathrm{Se}(0))$, selenite $(\mathrm{Se}(\mathrm{IV}))$, and selenate $(\mathrm{Se}(\mathrm{VI}))$ [3]. Selenate and selenite are the most common chemical forms in surface waters. The standard of selenium in drinking water was set to $0.05 \mathrm{mg} / \mathrm{L}$ by the United States Environment Protection Agency (USEPA) [4].

Several researchers summarized treatment technologies for selenium removal from drinking water and wastewater. Methods of treatment technologies include precipitation, adsorption, ion exchange, membrane processes [1, 5-7]. Recently, the adsorption using an iron containing adsorbents has been investigated intensively to remove selenium from aqueous solutions, including iron oxide and hydroxides [8], layered double hydroxides $[9,10]$ and binary oxide [11]. Layered double hydroxide, also known as hydrotalcite-like [12] compounds are a large group of natural and synthetic layered materials and have received considerable attention in recent years due to their particular structures and unique applications such as a catalyst for oxygen evolution reaction [13]. Due to the ease of the exchangeability of LDH interlayer anions with other anions, they have been applied for the adsorption of many harmful organic and inorganic compounds in an aqueous medium. More recently, Sajid and Basheer reviewed LDH applications as emerging sorbent materials for analytical extractions and excellent adsorbing properties of LDH [14]. There is a large number of group of materials with cationexchange capabilities. The number of systems with positively charged frameworks or layers are extremely limited [12]. To the best of our knowledge, there is no

(C) The Author(s). 2019 Open access. This article is distributed under the terms of the Creative Commons Attribution 4.0 International License (http://creativecommons.org/licenses/by/4.0/), which permits unrestricted use, distribution, and reproduction in any medium, provided you give appropriate credit to the original author(s) and the source, provide a link to the Creative Commons license, and indicate if changes were made. 
research on adsorption capability of selenium on Fe-Mn $\mathrm{LDH}$ and Fe-Mn Dos and their comparison. The aim of this study is to evaluate the adsorption capacity of Se (IV) and $\mathrm{Se}(\mathrm{VI})$ from aqueous solutions to examine the possibility of using synthetic Fe-Mn LDHs and Fe-Mn DOs.

\section{EXPERIMENTAL}

Materials: All chemicals are analytical grade and purchased from Sigma Aldrich Co., Ltd. Selenium stock solutions were prepared by dissolving $\mathrm{Na}_{2} \mathrm{SeO}_{3}$ and $\mathrm{Na}_{2} \mathrm{SeO}_{4}$ in deionized water. Selenium working solutions were freshly prepared by diluting $\mathrm{Se}(\mathrm{IV})$ and $\mathrm{Se}(\mathrm{VI})$ solutions with deionized water.

Preparation of Fe-Mn LDHs and Fe-Mn Dos: Fe-Mn LDH was synthesized using the traditional coprecipitation method. In a typical procedure, $0.1 \mathrm{M}$ of $\mathrm{Mn}\left(\mathrm{NO}_{3}\right)_{2} \cdot 6 \mathrm{H}_{2} \mathrm{O}$ and $0.1 \mathrm{M}$ of $\mathrm{Fe}\left(\mathrm{NO}_{3}\right)_{3} \cdot 9 \mathrm{H}_{2} \mathrm{O}$ were dissolved in $500 \mathrm{ml}$ distilled water (Solution 1). Solution 2 was prepared by dissolving $0.1 \mathrm{M}$ of $\mathrm{Na}_{2} \mathrm{CO}_{3}$ in 400 $\mathrm{ml}$ distilled water. Solution 1 and 2 was added into $1 \mathrm{~L}$ distilled water under constant stirring at a temperature of $25^{\circ} \mathrm{C}$ (at ambient temperature). The $\mathrm{pH}$ of the mixed solution was kept at ten by adjusting $1 \mathrm{M} \mathrm{NaOH}$. The resulting suspension was aged at $60{ }^{\circ} \mathrm{C}$ for $4 \mathrm{~h}$. Then the final suspension was separated from the solution by a filter paper and washed with distilled water. The filtrate solid sample dried at $50{ }^{\circ} \mathrm{C}$ for $24 \mathrm{~h}$ to obtain the Fe-Mn LDH. Finally, the powder of the Fe-Mn LDH was calcined at $450{ }^{\circ} \mathrm{C}$ for 4 hours to form Fe-Mn DO.

The morphological, structural and chemical characterizations of the materials are analyzed using Scanning Electron Microscope (SEM, S-3400N, Hitachi, Japan) equipped with Energy Dispersive X-ray (EDX), X-ray diffraction (XRD, X-MAX=200-PC, Rigaku Co., Japan) and Fourier Transform Infrared Spectrometry (FTIR, Jasco, FT/IR-6600, Japan). pH values were measured with a digital $\mathrm{pH}$ meter $(\mathrm{pH} 300$, Hanna Instruments, Italy).

A mass of $0.1 \mathrm{~g}$ of Fe-Mn LDHs and Fe-Mn DOs was separately mixed with $25 \mathrm{ml}$ of $100 \mathrm{mg} / \mathrm{L}$ selenite solution in $50 \mathrm{~mL}$ polyethylene tube in order to investigate adsorption kinetics. The samples were shaken by an over-head shaker at various time intervals $(5,10$, 20, $30 \mathrm{~min}, 1,2,3,4,5,6,12 \mathrm{~h}$, and $24 \mathrm{~h}$ ). Then, the samples were centrifuged at $3500 \mathrm{rpm}$ for $10 \mathrm{~min}$. The $\mathrm{Se}(\mathrm{IV})$ adsorption kinetic data were correlated with the adsorption kinetic models: Pseudo-first-order equation:

$$
\log \left(q_{e}-q_{t}\right)=\log q_{e}-\frac{K_{1}}{2.303} t
$$

Where, $q_{e}$ and $q_{t}$ are the amount of oxy metal anion adsorbed at equilibrium and time $(\mathrm{mg} / \mathrm{g})$, respectively, and $\mathrm{K}_{1}$ is the equilibrium rate constant of Pseudo firstorder adsorption, (1/min). The pseudo-second order model has the following:

$$
\frac{t}{q_{t}}=\frac{1}{K_{2} q_{e}^{2}}+\frac{t}{q_{e}}
$$

Where, $\mathrm{K}_{2}$ is the equilibrium rate constant of Pseudo second-order adsorption ( $/ \mathrm{mg} \cdot \mathrm{min})$. The Elovich model equation is generally expressed:

$$
q_{t}=\frac{1}{\beta} \ln (\alpha \beta)+\frac{1}{\beta} \ln (t)
$$

If oxy metal anion adsorption fits the Elovich model, a plot of $q_{t}$ various $\ln (t)$ should yield a linear relationship with a slope of $(1 / \beta)$ and an intercept of $(1 / \beta) \ln (\alpha \beta)$. The intra-particle diffusion model is expressed:

$$
\log R=\log K_{i d}+\operatorname{alog}(t)
$$

Where, $\mathrm{R}$ is the percent of arsenic adsorbed, is a rating factor.

For adsorption isotherm, a mass of $0.1 \mathrm{~g}$ of Fe-Mn LDHs and Fe-Mn DOs was mixed with $25 \mathrm{~mL}$ of various concentrations of selenite solution in $50 \mathrm{~mL}$ polyethylene tube. $0.1 \mathrm{~g} \mathrm{Fe-Mn} \mathrm{LDHs} \mathrm{and} \mathrm{Fe-Mn} \mathrm{DOs} \mathrm{were} \mathrm{mixed} \mathrm{with}$ $25 \mathrm{~mL}$ selenite solution of $100 \mathrm{mg} / \mathrm{l}$ in the polyethylene tube in order to evaluate the $\mathrm{pH}$ effect on the adsorption of selenite. $0.1 \mathrm{M} \mathrm{HNO}_{3}$ and $0.1 \mathrm{M} \mathrm{NaOH}$ were used to add $0.1,0.5,1,3,5,10 \mathrm{ml}$ respectively. The samples were equilibrated for $24 \mathrm{~h}$ at $100 \mathrm{rpm}$ on an orbital shaker, and centrifugation has been performed all of the samples. The residual concentration of $\mathrm{Se}(\mathrm{IV})$ in the solution was measured by a standard method and total selenium concentration in the supernatant determined by ICP-OES. The Se(IV) adsorption isotherm data were calculated with the theoretical models of Langmuir, Freundlich, Temkin, and Dubinin-Radushkevich isotherm model.

Langmuir isotherm model:

$$
q_{e}=\frac{\mathrm{Q}_{\max } K_{L} C_{e}}{1+K_{L} C_{e}}
$$

Where $\mathrm{q}_{\mathrm{e}}$ and $\mathrm{q}_{\max }$ are the equilibrium and maximum adsorbed amount of $\mathrm{Se}$ (IV) ion onto Fe-Mn LDH and Fe-Mn DOs, respectively, $\mathrm{K}_{\mathrm{L}}$ is constant related to the adsorption energy $(\mathrm{L} / \mathrm{mg})$ and should vary with temperature, $\mathrm{C}_{e}$ is the equilibrium selenium concentration (mg/L).

The Freundlich isotherm model:

$$
\mathrm{q}_{e}=K_{F} C_{e}^{1 / n}
$$

Where is the Freundlich constant and $\mathrm{n}$ the Freundlich exponent.

The Temkin isotherm model:

$$
q_{e}=\frac{R T}{b} \ln A+\frac{R T}{b} \ln C_{e}
$$

Where; $\quad \frac{R T}{b}=B$

Therefore a plot of $q_{e}$ versus in $C_{e}$ enables one to determine the constants $A$ and $B$. The DubininRadushkevich isotherm model:

$$
\ln q_{e}=\ln q_{m}-\beta \varepsilon^{2}
$$


Where $q_{m}$ is the Dubinin-Radushkevich monolayer capacity $(\mathrm{mg} / \mathrm{g}), \beta$ a constant related to adsorption energy, and $\varepsilon$ is the Polanyi potential which is related to the equilibrium concentration as follows:

$$
\varepsilon=R T \ln \left(1+\frac{1}{C_{e}}\right)
$$

Where $R$ is the gas constant $(8.314 \mathrm{~kJ} / \mathrm{mol} \cdot \mathrm{K}), T$ is absolute temperature $(\mathrm{K})$. The Constant $\beta$ gives the mean free energy (E) of adsorption per molecule of the adsorbate when it is transferred to the surface of the solid form infinity in the solution and can be computed using the relationship:

$$
E=\frac{1}{\sqrt{2 \beta}}
$$

The thermodynamic parameters that must be considered to determine the adsorption processes were changes in standard enthalpy $\left(\Delta H^{\circ}\right)$, standard entropy $\left(\Delta S^{\circ}\right)$, standard free energy $\left(\Delta G^{\circ}\right)$ due to transfer of unit mole of solute from solution onto the solid-liquid interface. The thermodynamic parameters determined by the free energy of the Gibbs. Gibbs free energy equation has the following:

$$
\Delta G^{\circ}=\Delta H^{\circ}-T \Delta S^{\circ}=-\mathrm{RT} \ln K_{L}
$$

Where $\Delta H^{\circ}$ is standard enthalpy, $\Delta S^{\circ}$ is standard entropy, $\Delta S^{\circ}$ is standard free energy, $\mathrm{R}$ is the gas constant $(8.314 \mathrm{~kJ} / \mathrm{mol} \cdot \mathrm{K}), \mathrm{T}$ is absolute temperature, and is Langmuir constant.
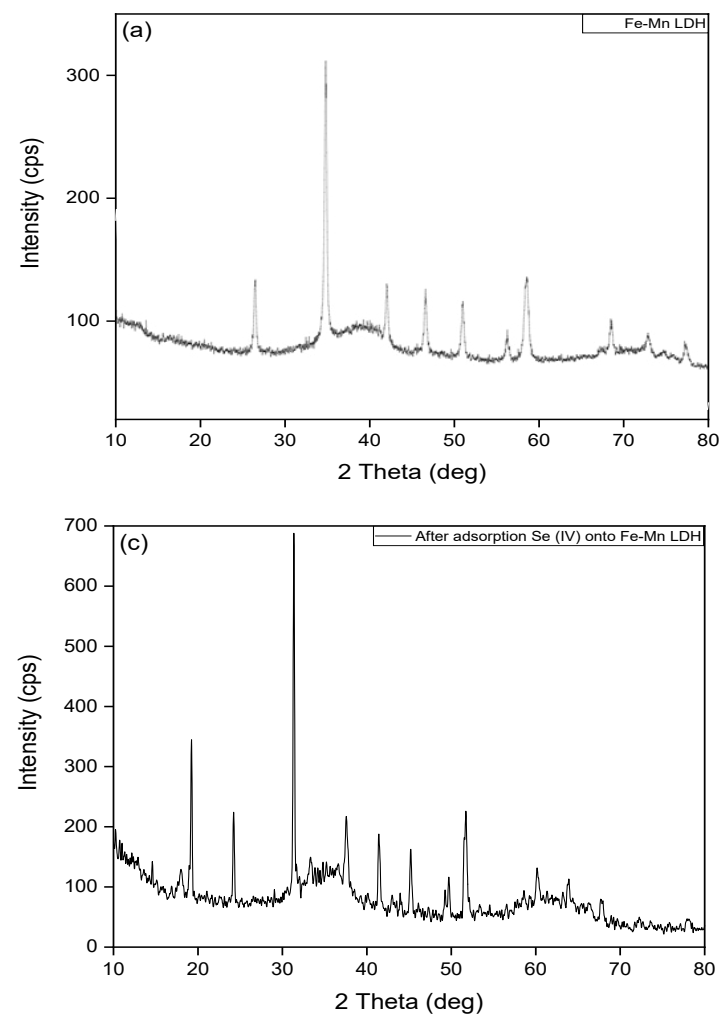

The value of $\Delta H^{\circ}$ and $\Delta S^{\circ}$ can be computed using the following equation:

$$
\ln K_{L}=\frac{\Delta H^{0}}{R T}+\frac{\Delta S^{0}}{R}
$$

Repeated adsorption and desorption experiments: The desorption of selenite was tested in order to test the repeated use of Fe-Mn LDH and Fe-Mn DOs. Firstly, 0.1 $\mathrm{g}$ of Fe-Mn LDHs and Fe-Mn DOs were mixed with 25 $\mathrm{ml}$ of selenite containing $100.0 \mathrm{mg} / \mathrm{L}$, then equilibrated for 1 hour. After centrifugation, the supernatant was taken out and analyzed, and $25 \mathrm{~mL}$ of $0.1 \mathrm{M} \mathrm{NaOH}$ or $\mathrm{Na}_{2} \mathrm{CO}_{3}$ solution was added into the bottle. After then, the mixture was shaken to desorb $\mathrm{Se}$ (IV) from the FeMn LDHs and Fe-Mn DOs. After mixing for 1 hour, the mixture was centrifuged, and the supernatant for further analysis. This cycle was repeated 5 times.

Column experiments: For column experiments, FeMn LDHs and Fe-Mn DOs (2 g) were packed into a glass column (10 $\mathrm{mm}$ inner diameter) fitted with glass wool at the bottom and top. Aqueous solutions of $\mathrm{Se}(\mathrm{IV})$ with $2 \mathrm{mg} / \mathrm{L}$ was continuously passed through the column from bottom to top at a constant rate (35 $\mathrm{mL} / \mathrm{h}$ ) at room temperature using a Masterflex L/S pump (Cole Parmer 7524-45, USA). After a periodic sampling of the affluent, the sample was analyzed to determine selenium concentration.

\section{RESULTS AND DISCUSSION}

$X$-ray diffraction analysis: The $X$-ray diffraction patterns of Fe-Mn LDHs are shown in Figure 1a.
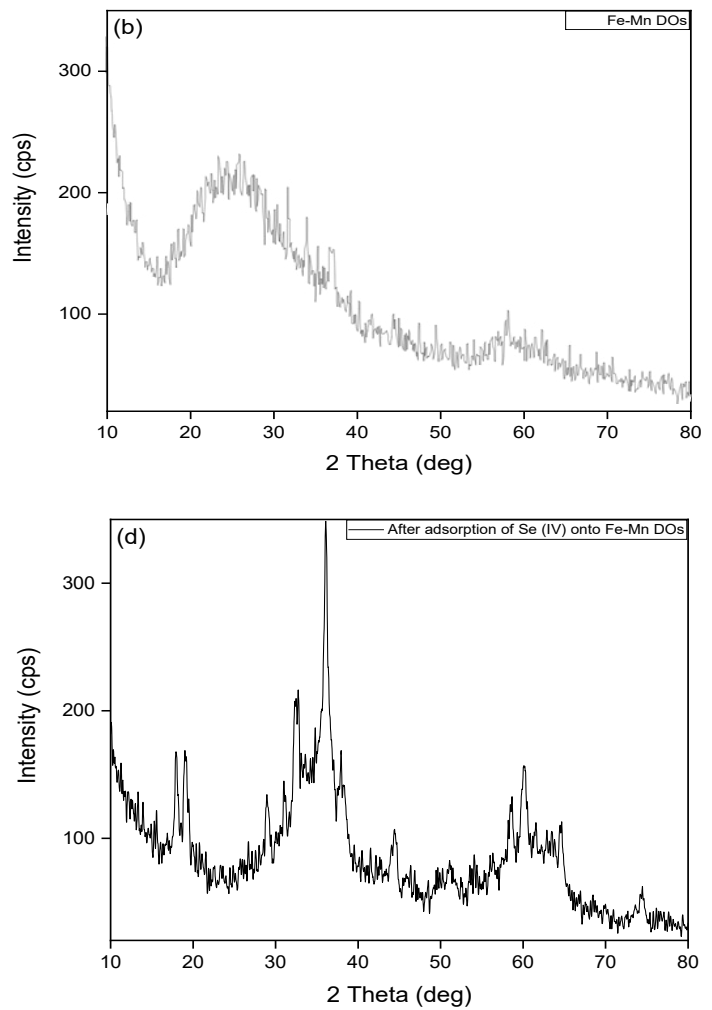

Fig. 1. XRD patterns of Fe-Mn LDHs before a) and after ion exchange reaction c) of selenite and Fe-Mn DOs before b) and after d) adsorption by Se(IV). 

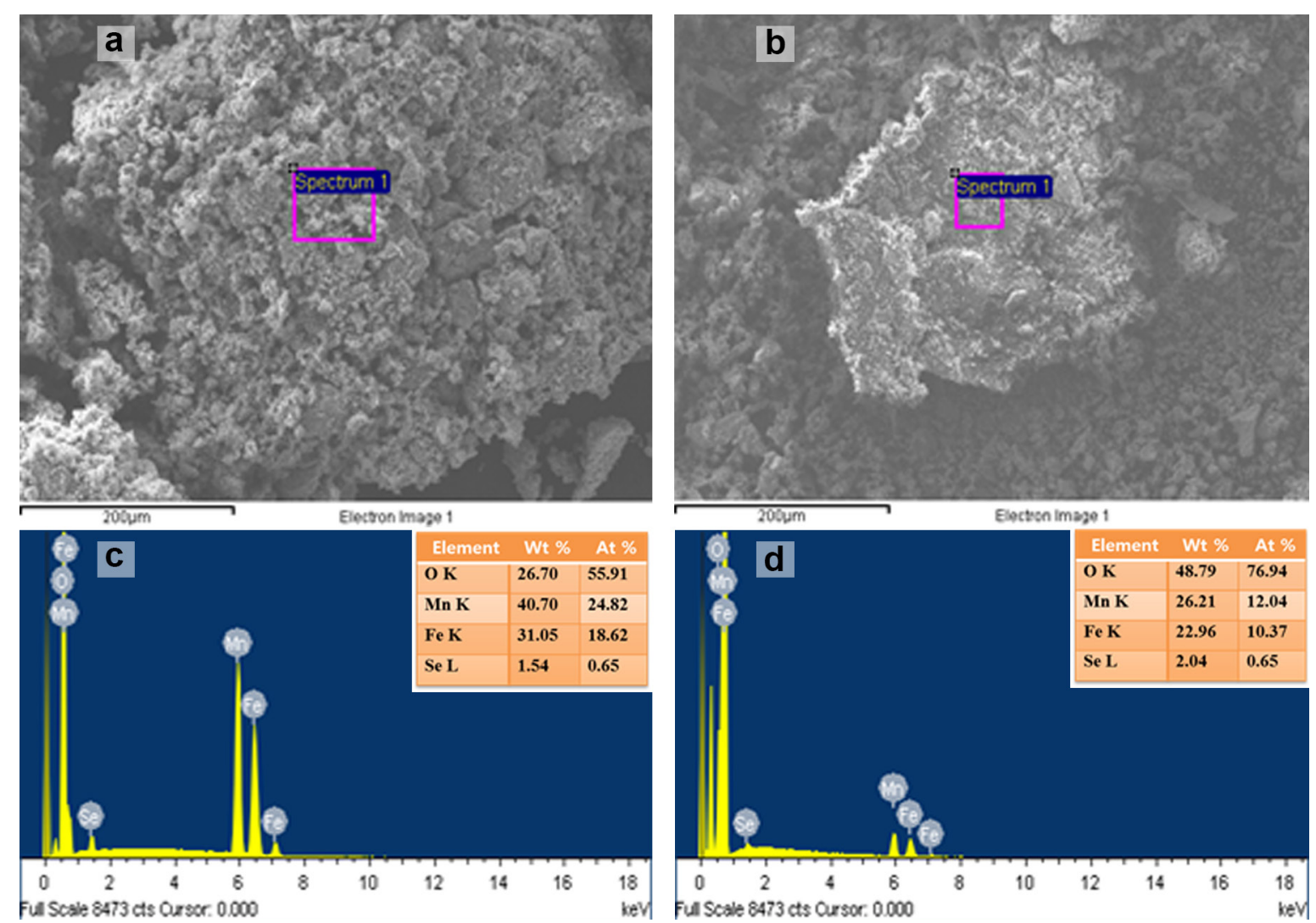

Fig. 2. SEM image and SEM-EDX after adsorption of Se(IV) on Fe-Mn LDHs (a) and (c) and those after adsorption of $\mathrm{Se}(\mathrm{IV})$ onto Fe-Mn Dos (b) and (d).

The results suggest that the synthetic Fe-Mn LDHs were constructed to well-ordered layered structures. Our synthesized materials were based on the structure of manganese carbonate.

However, the adsorption added one new reflection peak at $19.24^{\circ}$ in Figure 1c. Probably, the Mn-Se-Fe inner or outer-sphere complex was synthesized on the surface of Fe-Mn LDHs. The amorphous structure of Fe-Mn Dos is shown in Figure 1b. After the adsorption process of $\mathrm{Se}(\mathrm{VI})$ onto Fe-Mn Dos, the crystalline peak was detected at $19.35^{\circ}$ by XRD analysis showed in Figure $1 \mathrm{~d}$. Very low intensity Fe-Mn hydroxide peaks were observed on the surface of Fe-Mn DOs.

SEM image SEM-EDX analysis: SEM images and SEM-EDX results of Fe-Mn LDHs are shown in Figure 2. The EDX result shows selenite ion onto Fe-Mn LDHs. Probably, the carbonate in the interlayer of Fe-Mn LDHs was interchanged with selenite. The SEM image of the Fe-Mn Dos shows that the material was constituted by many aggregated small particles, which led to a rough surface and the presence of a porous structure. The EDX analysis (Figure 2c, 2d) revealed that the molar ratio of $\mathrm{Mn} / \mathrm{Fe}$ was 1.31 and 1.14 for $\mathrm{Fe}-\mathrm{Mn}$ LDHs and $\mathrm{Fe}-\mathrm{Mn}$ DOs, respectively, which is consistent with the initial ratio of $\mathrm{Mn} / \mathrm{Fe}$. The Fe-Mn LDHs after ion exchange reaction by selenium might change carbonate into selenite in the interlayer. The iron oxide surface might provide the adsorption site for selenite ion on the surface of Fe-Mn DOs.
FTIR spectra analysis: The original peaks of Fe-Mn LDHs and Fe-Mn DOs are shown in Figure 3.
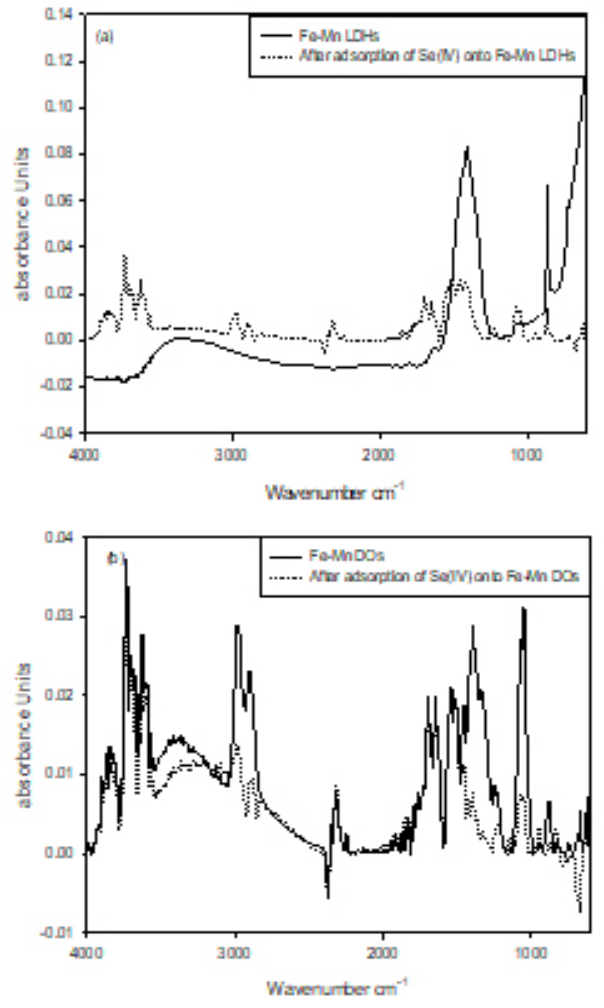

Fig. 3. FTIR spectra of after adsorption of Se(IV) by Fe-Mn LDHs and Fe-Mn DOs. 
After the adsorption process, the broad peak of LDH at 1402 and $860 \mathrm{~cm}^{-1}$ was reduced, and a new band of $\mathrm{Se}(\mathrm{IV})$ is shown only at $948 \mathrm{~cm}^{-1}$. In the case of Fe-Mn DOs, the adsorption of Se (IV) weakened the intensity peak at $865 \mathrm{~cm}^{-1}$, significantly.

Adsorption study of Se (IV) on the Fe-Mn LDHs and Fe-Mn DOs: Figure 4 shows the kinetics of Se (IV) and Se (VI) adsorption on Fe-Mn LDHs and Fe-Mn DOs. As shown in Figure 4, our synthesized adsorbents do not remove $\mathrm{Se}(\mathrm{VI})$. Some researchers reported that chemical clarification with lime, ferric sulfate, aluminum sulfate, and activated carbon adsorption are moderately sufficient to remove Se(IV) from water. However, all methods were ineffective in removing

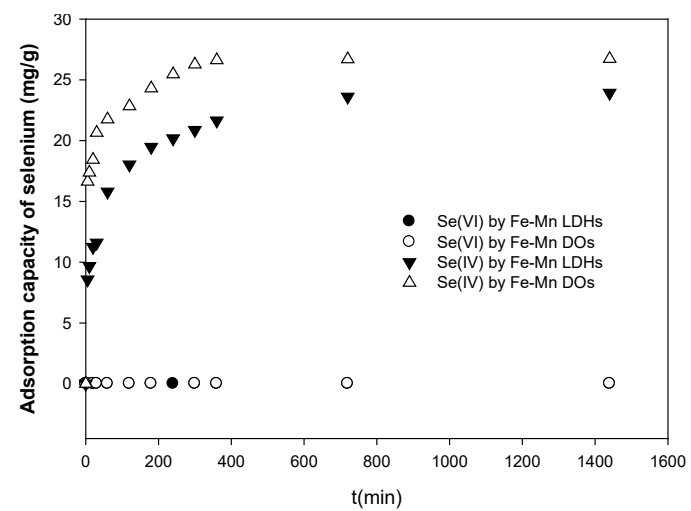

Fig. 4. Adsorption kinetics of $\mathrm{Se}(\mathrm{IV}), \mathrm{Se}(\mathrm{VI})$ by Fe-Mn LDHs and Fe-Mn DOs

$\mathrm{Se}(\mathrm{VI})$ [15]. Therefore, we focused on the removal of $\mathrm{Se}(\mathrm{IV})$. Se(IV) adsorption process by Fe-Mn LDH and $\mathrm{Mn}-\mathrm{Fe}$ DOs reached equilibrium within $6 \mathrm{~h}$. The four different kinetic models fitted to the experimental data. The removal mechanism of Se(IV) by Fe-Mn LDH is an ion-exchange step as following $[16,17]$ :

$$
\mathrm{S}_{\mathrm{LDH}^{-}}-\mathrm{CO}_{3}{ }^{2}+\mathrm{SeO}_{3}^{-} \rightarrow \mathrm{S}_{\mathrm{LDO}} \mathrm{SeO}_{3}+\mathrm{CO}_{3}{ }^{2-}
$$

Additionally, the surfaces of Fe-Mn LDHs and Fe-Mn DOs are protonated at low $\mathrm{pH}$ and have a positive charge.

$$
\mathrm{S}_{\mathrm{Fe}-\mathrm{Mn}}-\mathrm{O}+\mathrm{H}_{3} \mathrm{O}^{+} \rightarrow \mathrm{S}_{\mathrm{Fe}-\mathrm{Mn}}-\mathrm{OH}^{+}+\mathrm{H}_{2} \mathrm{O}
$$

The interaction between the positively charged surfaces and anions is another removal mechanism for Se(IV) removal.

$$
\begin{gathered}
\mathrm{S}_{\mathrm{Fe}-\mathrm{Mn}}-\mathrm{OH}+\mathrm{H}^{+}+\mathrm{SeO}_{3}^{2-} \rightarrow \mathrm{S}^{-\mathrm{SeO}_{3}-}+\mathrm{H}_{2} \mathrm{O} \\
\mathrm{S}_{\mathrm{Fe}-\mathrm{Mn}}-\mathrm{OH}+2 \mathrm{H}^{+}+\mathrm{SeO}_{3}{ }^{2-} \rightarrow \mathrm{S}-\mathrm{HSeO}_{3}^{-}+\mathrm{H}_{2} \mathrm{O}
\end{gathered}
$$

Where, $\mathrm{S}$ the surface of Fe-Mn LDHs and Fe-Mn DOs. The adsorption kinetics of selenium adsorption on FeMn LDHs and Fe-Mn DOs and model parameters are plotted in Figure 4 and Table 1. The pseudo-second order model was more fitted with empirical data. It was meant to be the adsorption of Se(IV) onto Fe-Mn LDHs as chemisorption or the diffusion process. When chemisorption or intra-particle diffusion is involved in the adsorption of $\mathrm{Se}(\mathrm{IV})$, the relationship between the adsorbed amount of selenium anions and the square root of time would be linear. As shown in Figure 4, the relationship was linear, and this is evidence of

\begin{tabular}{|c|c|c|c|c|c|c|c|}
\hline \multirow[b]{2}{*}{ Species } & \multicolumn{3}{|c|}{ Pseudo-first-order } & \multicolumn{4}{|c|}{ Pseudo-second-order } \\
\hline & $\begin{array}{l}\mathrm{q}_{\mathrm{e}} \\
\mathrm{mg} / \mathrm{g}\end{array}$ & $\begin{array}{l}\mathrm{K}_{1} \\
1 / \mathrm{min}\end{array}$ & $\mathrm{r}^{2}$ & $\begin{array}{l}\mathrm{q}_{\mathrm{e}} \\
\mathrm{mg} / \mathrm{g}\end{array}$ & \multicolumn{2}{|c|}{$\begin{array}{l}\mathrm{K}_{2} \\
\mathrm{mg} / \mathrm{g} \cdot \mathrm{min}\end{array}$} & $\mathrm{r}^{2}$ \\
\hline Fe-Mn LDH & 20.841 & 0.037 & 0.935 & 24.367 & \multicolumn{2}{|c|}{0.001} & 0.999 \\
\hline Fe-Mn DOs & 24.227 & 0.151 & 0.935 & 26.949 & \multicolumn{2}{|c|}{0.003} & 0.999 \\
\hline \multirow{2}{*}{ Species } & \multicolumn{3}{|c|}{ Elovich model } & \multicolumn{4}{|c|}{ Intra-particle diffusion } \\
\hline & $\beta, \mathrm{g} / \mathrm{mg}$ & $\alpha, \mathrm{mg} /$ & $\mathrm{g} \cdot \min \mathrm{r}$ & $r^{2}$ & $\mathrm{~K}_{\mathrm{id}}$ & a & $r^{2}$ \\
\hline Fe-Mn LDH & 0.32 & 7.40 & & 0.98 & 4.14 & 0.20 & 0.96 \\
\hline Fe-Mn DOs & 0.47 & 988.87 & & 0.95 & 5.65 & 0.10 & 0.95 \\
\hline
\end{tabular}
chemisorption [18].

Table 1. Summary of Se(IV) adsorption kinetics parameters by Fe-Mn DOs and Fe-Mn LDHs

Adsorption isotherm of Se (IV) onto Fe-Mn LDHs and Fe-Mn DOs: The adsorption of Se(IV) from solution by Fe-Mn LDHs and Fe-Mn DOs was fitted to both the Langmuir, Freundlich, Temkin, and DubininRadushkevich adsorption isotherm models shown in Figure 5 and Table 2. The adsorption isotherm studies were carried out in the temperature range of $283-323 \mathrm{~K}$. The Freundlich isotherm plot shows a good correlation for all ranges of temperatures between 0.94 and 0.99 . Also, the Langmuir isotherm model determined adsorption capacity $\left(Q_{\max }\right)$ of $\mathrm{Se}(\mathrm{IV})$ onto Fe-Mn LDHs and Fe-Mn DOs as $0.6 \mathrm{mM} / \mathrm{g}$ and $0.7 \mathrm{mM} / \mathrm{g}$, respectively. Langmuir isotherm model assumes site-specific monolayer adsorption, and the Freundlich isotherm model means a multi-layer adsorption process. Temkin isotherm model assumes interactions between $\mathrm{Se}(\mathrm{VI})$ anion and the adsorbents by a uniform distribution of binding energies. The Dubinin-Radushkevich isotherm model determined free energy $(E)$ of adsorption kinetics, where the values were ranged between 4 to $8 \mathrm{~kJ} / \mathrm{mol}$ in the $\mathrm{Fe}-\mathrm{Mn} \mathrm{LDH}$, and Fe-Mn DOs, which the adsorption process occurs physically. The thermodynamic parameters determined by changes in Gibbs free energy $\Delta G^{\circ}$. The changes of standard enthalpy $\Delta \mathrm{H}^{\circ}$ and entropy $\Delta \mathrm{S}^{\circ}$ were calculated (Figure 6). The $\Delta \mathrm{H}^{\circ}$ and $\Delta \mathrm{S}^{\circ}$ were computed as -167.27 $\mathrm{J} / \mathrm{mol}$ and $0.596 \mathrm{~J} / \mathrm{mol} \cdot \mathrm{K}$ for Fe-Mn LDHs and 92.53 $\mathrm{J} / \mathrm{mol},-0.165 \mathrm{~J} / \mathrm{mol} \cdot \mathrm{K}$ for Fe-Mn DOs. The change of enthalpy is negative in an exothermic reaction and positive in an endothermic phenomenon. Natural porous adsorbents and clay materials are observed as negative changes in enthalpy. The enthalpy change has a negative value for LDH. Therefore, the increasing temperature increased anion-exchange, and adsorption occured Se(IV) onto interlayer or surface. 
Table 2. Summary of Se(IV) adsorption isotherm parameters by LDH, DOs

\begin{tabular}{|c|c|c|c|c|c|c|c|c|c|}
\hline \multirow{2}{*}{ Species } & \multirow{2}{*}{ Temp. K } & \multicolumn{4}{|c|}{ Langmuir isotherm } & \multicolumn{4}{|c|}{ Freundlich isotherm } \\
\hline & & $\mathbf{Q}_{\max }$ & $K_{L}$ & $r^{2}$ & & $\mathrm{~K}_{\mathrm{F}}$ & & \multirow{2}{*}{$\begin{array}{l}\mathbf{1 / n} \\
0.433\end{array}$} & $r^{2}$ \\
\hline \multirow{5}{*}{ Fe-Mn LDHs } & 283 & 0.610 & 0.974 & 0.986 & \multicolumn{3}{|c|}{0.271} & & 0.996 \\
\hline & 293 & 0.571 & 1.742 & 0.980 & \multicolumn{3}{|c|}{0.308} & 0.385 & 0.994 \\
\hline & 303 & 0.618 & 2.616 & 0.992 & \multicolumn{3}{|c|}{0.373} & 0.347 & 0.984 \\
\hline & 313 & 0.623 & 3.470 & 0.989 & \multicolumn{3}{|c|}{0.397} & 0.341 & 0.985 \\
\hline & 323 & 0.655 & 3.917 & 0.992 & \multicolumn{3}{|c|}{0.428} & 0.332 & 0.978 \\
\hline \multirow{5}{*}{ Fe-Mn DOs } & 283 & 0.544 & 25.510 & 0.946 & \multicolumn{3}{|c|}{0.456} & 0.234 & 0.984 \\
\hline & 293 & 0.599 & 15.129 & 0.949 & \multicolumn{3}{|c|}{0.507} & 0.241 & 0.982 \\
\hline & 303 & 0.651 & 12.821 & 0.960 & \multicolumn{3}{|c|}{0.526} & 0.234 & 0.988 \\
\hline & 313 & 0.671 & 12.594 & 0.959 & \multicolumn{3}{|c|}{0.553} & 0.202 & 0.983 \\
\hline & 323 & 0.700 & 10.764 & 0.949 & & 0.579 & & 0.175 & 0.949 \\
\hline \multirow{2}{*}{ Species } & \multirow{2}{*}{ Temp. K } & \multicolumn{3}{|c|}{ Temkin } & \multicolumn{5}{|c|}{ Dubinin - Radushkevich } \\
\hline & & B & A & $\mathbf{r}^{2}$ & $\mathbf{q}_{\max }$ & & $\beta$ & $\mathbf{E}$ & $r^{2}$ \\
\hline \multirow{5}{*}{ Fe-Mn LDHs } & 283 & 0.08 & 45.98 & 0.90 & 0.32 & & 0.02 & 4.55 & 0.84 \\
\hline & 293 & 0.09 & 53.60 & 0.95 & 0.38 & & 0.03 & 4.46 & 0.93 \\
\hline & 303 & 0.10 & 66.24 & 0.98 & 0.47 & & 0.02 & 4.59 & 0.97 \\
\hline & 313 & 0.10 & 74.53 & 0.99 & 0.51 & & 0.02 & 4.77 & 0.98 \\
\hline & 323 & 0.11 & 79.38 & 0.99 & 0.54 & & 0.02 & 4.95 & 0.99 \\
\hline \multirow{5}{*}{ Fe-Mn DOs } & 283 & 0.07 & 1107.90 & 0.98 & 0.54 & & 0.01 & 6.87 & 0.93 \\
\hline & 293 & 0.08 & 1211.22 & 0.98 & 0.56 & & 0.01 & 7.26 & 0.95 \\
\hline & 303 & 0.08 & 1440.05 & 0.99 & 0.59 & & 0.01 & 7.72 & 0.95 \\
\hline & 313 & 0.08 & 942.21 & 0.99 & 0.60 & & 0.01 & 8.19 & 0.92 \\
\hline & 323 & 0.10 & 476.13 & 0.99 & 0.67 & & 0.01 & 5.95 & 0.97 \\
\hline
\end{tabular}
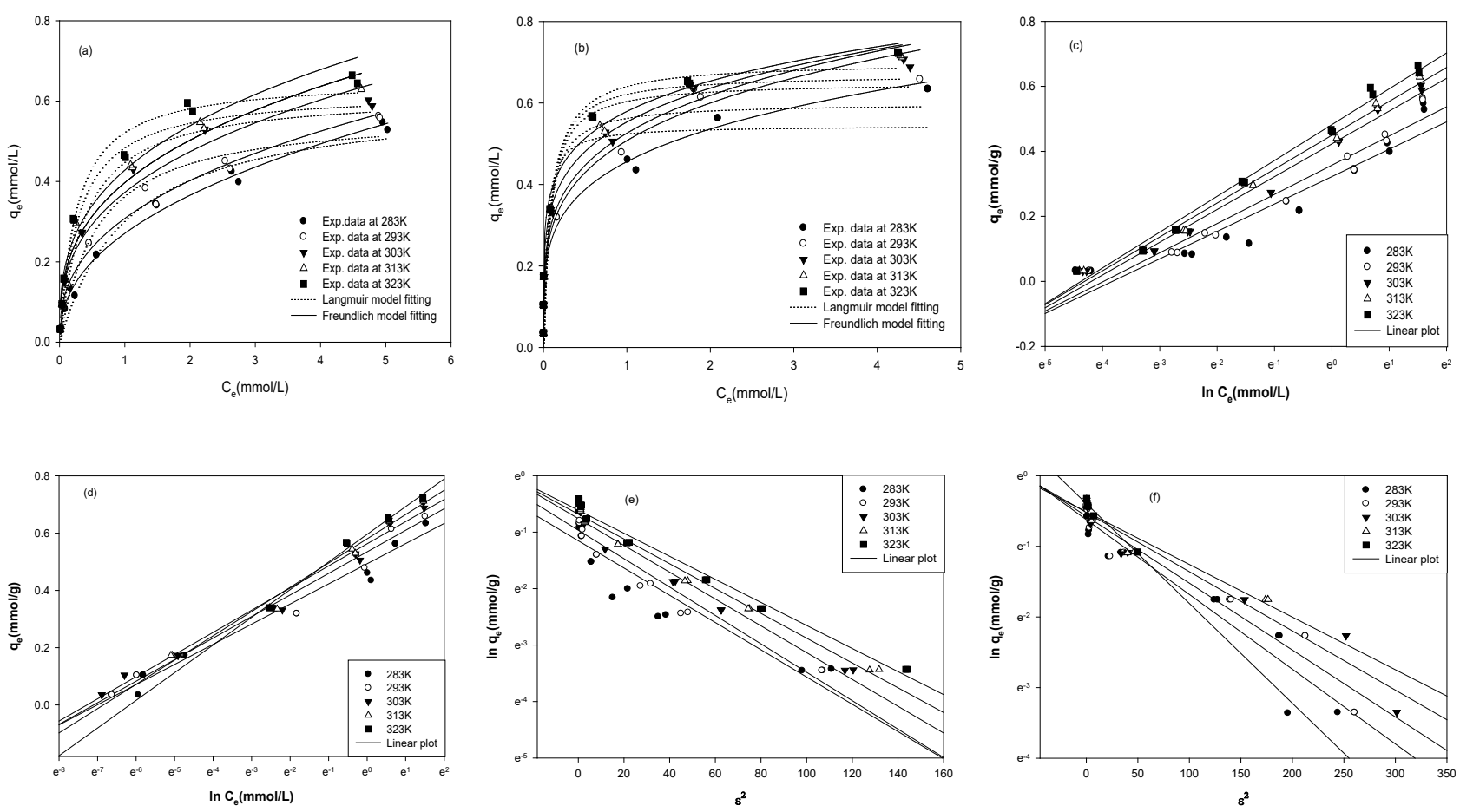

Fig. 5. Adsorption isotherm of Se(IV) by Fe-Mn LDHs and Fe-Mn DOs. a, c, d - Fe-Mn LDHs; b, d, f - Fe-Mn DOs; a, b - Langmuir and Freundlich; c, d - Temkin Isotherm and e, f - Dubinin-Radushkevich isotherm models 

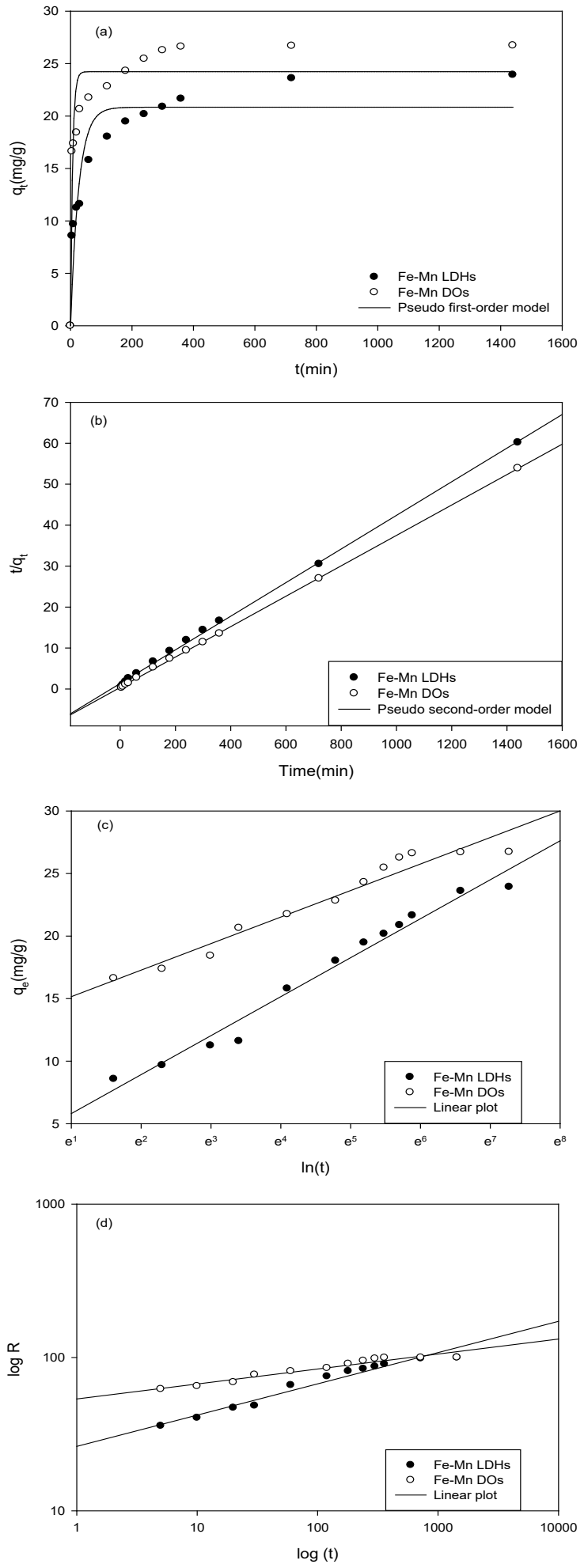

Fig. 6. Adsorption kinetic models fitting of Se(IV) by the Fe-Mn LDHs and Fe-Mn DOs, (a) Adsorption amount and Pseudo first-order model, (b) Pseudo-second order model, (c) Elovich model and (d) Intra-particle model

Fe-Mn LDHs and Fe-Mn DOs spontaneously adsorption process of $\mathrm{Se}(\mathrm{IV})$ based on the change of Gibbs free energy.
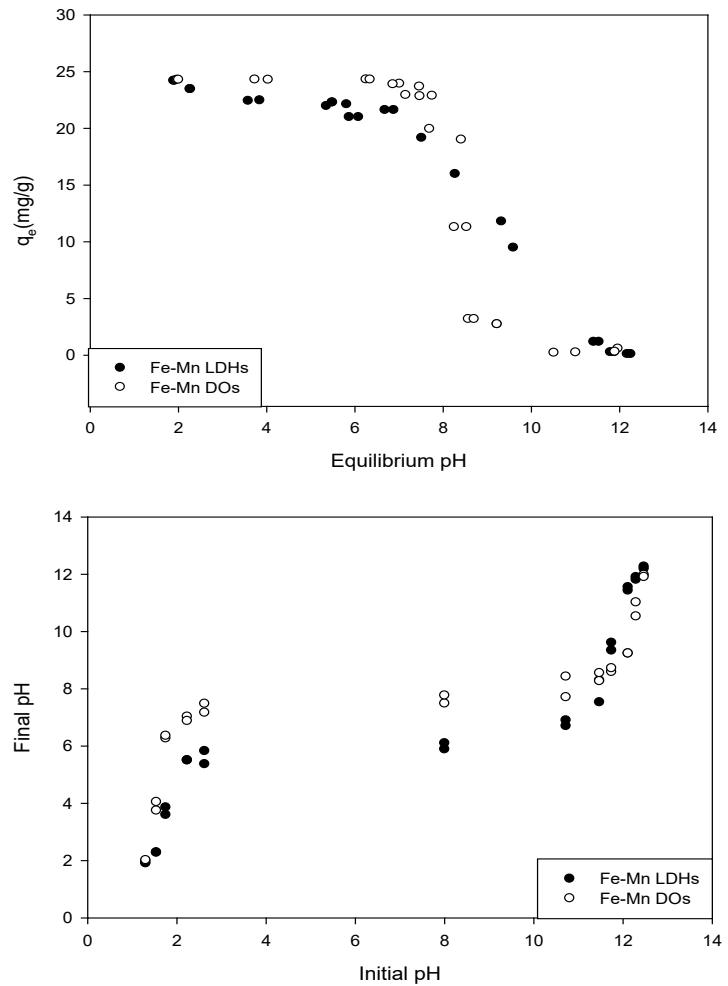

Fig. 7. The pH effect on the removal of Se (IV) by Fe-Mn LDHs and Fe-Mn DOs

pH Effect: The pH effect on the adsorption of Se(IV) was investigated and shown in Figure 7. The adsorption decreases very sharply at the $\mathrm{pH}$ range above 7.0 because the surface charge changed to negative due to the deprotonation of the surface. Generally, natural and synthetic metal adsorbents can be adsorbed $\mathrm{Se}$ (IV) more effective in the acidic solutions because this surface is positively charged at acidic conditions. A similar result was reported by Zhang et al. [19], to remove Se(IV) using an iron-coated GAC adsorbent. The $\mathrm{pH}$ dependent adsorption behavior can be explained by the release of $\mathrm{OH}^{-}$upon the adsorption of anions or weak acids onto Fe-Mn LDH and Fe-Mn DOs.

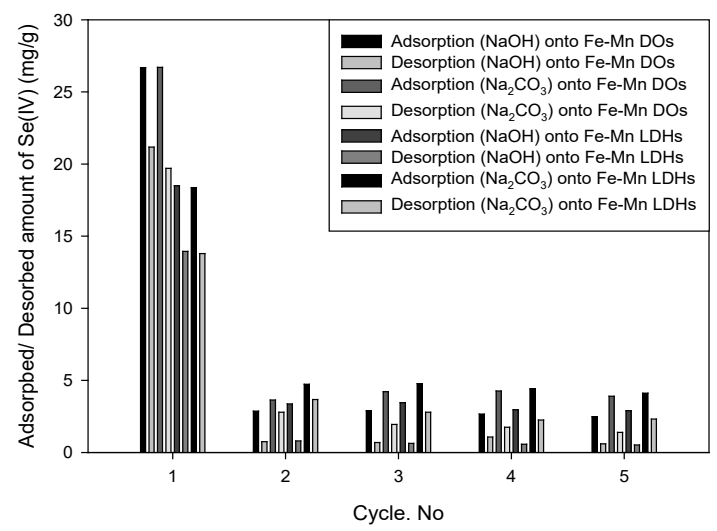

Fig. 8. Adsorption/Desorption cycle 
Table 3. Adsorption characteristics of Selenium onto Fe-Mn LDH compared to various LDHs

\begin{tabular}{|c|c|c|c|c|c|c|c|c|}
\hline Types & Method & $Q_{\max } \mathrm{mg} / \mathrm{g}$ & Model & $\mathrm{C}_{0} \mathrm{mg} / \mathrm{L}$ & $\mathrm{pH}$ & Temp. ${ }^{\circ} \mathrm{C}$ & $S / L$ ratio & Reference \\
\hline Calcined Mg-Al-Zr $\left(450^{\circ} \mathrm{C}\right)$ & C & 29.0 & $\mathrm{~L}$ & & 6 & 30 & $1: 2000$ & Das et al. (2004) \\
\hline Mg-Al LDH & C & 120.1 & L & & 7 & & $1: 100$ & Youwen You (2001) \\
\hline Zn-AI LDH & C & 98.8 & L & & 7 & & $1: 100$ & Youwen You (2001) \\
\hline $\mathrm{Fe}-\mathrm{Mn}-\mathrm{CO}_{3} \mathrm{LDH}$ & C & 52.5 & L & $5-500$ & 7 & $10-50$ & $1: 250$ & This study \\
\hline $\mathrm{Al}(\mathrm{III}) / \mathrm{SiO}_{2}$ binary oxide & & 32.7 & L & $0-237$ & 5 & 25 & & Ya Ting Chan (2009) \\
\hline $\mathrm{Fe}(\mathrm{III}) / \mathrm{SiO}_{2}$ binary oxide & & 20.4 & L & $0-237$ & 5 & 25 & & Ya Ting Chan (2009) \\
\hline Fe-Mn hydrous oxide & L & 26.7 & & $5-500$ & 6.5 & 22 & $1: 1000$ & Małgorzata (2012) \\
\hline Fe-Mn DOs & C & 55.3 & $\mathrm{~L}$ & $5-500$ & 7 & $10-50$ & $1: 250$ & This study \\
\hline
\end{tabular}

C- Co-precipitation mothod, L- Langmuir model, F- Freundlich model, $C_{0}$ - initial concentration, S/L- soil liquid ratio (g/L), $Q_{\max }{ }^{-}$adsorption capacities

Adsorption/desorption characteristics of $\mathrm{Se}$ (IV) onto Fe-Mn DOs and Fe-Mn LDHs: Repeated adsorption and desorption were studied in detail of $\mathrm{Se}(\mathrm{IV})$ on Fe-Mn DOs and Fe-Mn LDHs (Figure 8) using $\mathrm{NaOH}(0.1 \mathrm{M})$ and $\mathrm{Na}_{2} \mathrm{CO}_{3}$ as desorption solutions. Even though $\mathrm{NaOH}$ and $\mathrm{Na}_{2} \mathrm{CO}_{3}$ desorbed 70-80\% of adsorbed $\mathrm{Se}(\mathrm{IV})$, the second cycle of adsorption decreased dramatically $10-20 \%$ of the initial capacity.

The result indicates that the solution is effective to regenerate the adsorbent, but also the regenerate changes the surface characteristics, which is undesirable.

Adsorption characteristics of $\mathrm{Se}(\mathrm{IV})$ onto $\mathrm{Fe}$ Mn LDHs and Fe-Mn DOs in column: The column adsorption study indicated that Selenite had a shorter breakthrough time onto Fe-Mn LDH than Fe-Mn Dos which had a lower slope for the breakthrough curve shown in Figure 9.

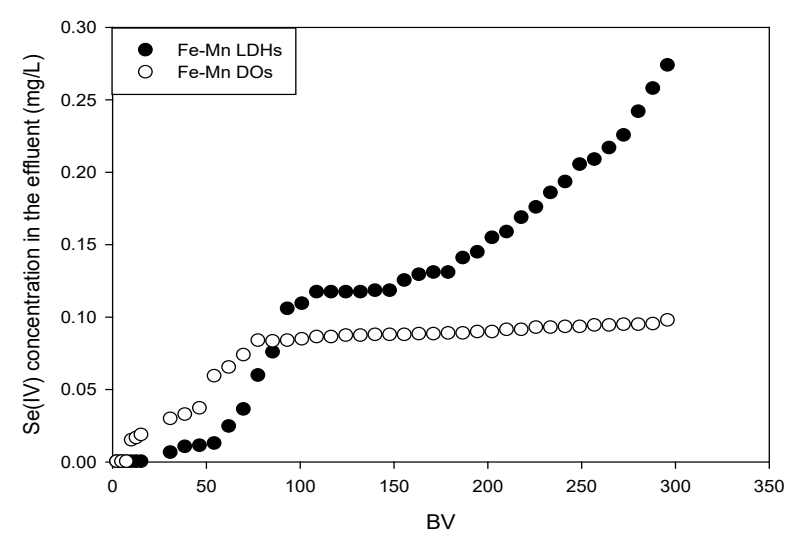

Fig. 9. Breakthrough curves of $\mathrm{Se}(\mathrm{IV})$ in column experiments.

It means there was a more significant mobilization of $\mathrm{Se}(\mathrm{IV})$ through the Fe-Mn LDH and Fe-Mn DOs columns. A similar conclusion was drawn by Xing Chang Zhang [19]. They described in detail of selenium by solving the inverse problem. Additionally, the stock solution of selenite adjusted to $\mathrm{pH} 7$, but this round described decrease adsorption capacity of selenite that is the deprotonated surface of Fe-Mn LDH and Fe-Mn DOs.
Table 3 summarizes the reported adsorption capacities and the same parameters of various LDHs for Se(IV) in the single oxyanion aqueous systems.

Our synthesized Fe-Mn LDH and Fe-Mn DO very efficiently removed $\mathrm{Se}(\mathrm{IV})$ from aqueous solutions, compared to various adsorbents. The Fe-Mn LDH and Fe-Mn DO have adsorption capacities for Se(IV) were 52.5 and $55.3 \mathrm{mg} / \mathrm{g}$, respectively, which are higher adsorption capacities than those of other adsorbents.

\section{CONCLUSIONS}

This result shows that Fe-Mn LDH and Fe-Mn DOs are very useful adsorbents to removing selenite from aqueous solutions. The selenite anion, as shown by the XRD, SEM-EDX, and FTIR, is incorporated into the interlayer and on the surface of Fe-Mn LDH and FeMn DOs. Adsorption kinetics and isotherm experiments were fitted well pseudo-second order model and Freundlich isotherm, respectively. The calculated Se (IV) adsorption capacity is 52.5 and $55.3 \mathrm{mg} / \mathrm{g}$ onto FeMn LDH and Fe-Mn DOs, respectively, for the Pseudo second-order model.

\section{ACKNOWLEDGMENTS}

This work was supported by the Korea Environment Industry and Technology Institute (KEITI) through the GAIA project, KIST, and the National University of Mongolia.

\section{REFERENCES}

1. Ruth E. Wolf, T.M.H., Philip L. Hageman, Suzette A. Morman, and G.S.P. (2010) Speciation of arsenic, selenium, and chromium in wildfire impacted soils and ashes, 1-29. https://pubs.usgs. gov/of/2010/1242/pdf/OF10-1242.pdf

2. Tan L.C., Nancharaiah, Y. V., Van Hullebusch E.D., Lens P.N.L. (2016) Selenium: environmental significance, pollution, and biological treatment technologies. Biotechnol. Adv., 34, 886-907. doi:10.1016/j.biotechadv.2016.05.005

3. Goh K.H., Lim T.T. (2004) Geochemistry of inorganic arsenic and selenium in a tropical soil: Effect of reaction time, $\mathrm{pH}$, and competitive anions on arsenic and selenium adsorption. 
Chemosphere, 55, 849-859. doi:10.1016/j. chemosphere.2003.11.041

4. WHO (2017) Guidelines for drinking-water quality, 4th edition, incorporating the 1st addendum, http:// www.who.int/water_sanitation_health/publications/ drinking-water-quality-guidelines-4-including-1staddendum/en/

5. Dadwhal M. (2010) Adsorption of trace levels of arsenic and selenium from aqueous solutions by conditioned layered double hydroxides. University of Southern California dissertations and thesises. The University of Southern California, (2010).

6. Bleiman N., Mishael Y.G. (2010) Selenium removal from drinking water by adsorption to chitosan-clay composites and oxides: Batch and columns tests. J. Hazard. Mater., 183, 590-595. doi:10.1016/j. jhazmat.2010.07.065

7. Dessì P., Jain R., Singh S., Seder-Colomina M., et al. (2016) Effect of temperature on selenium removal from wastewater by UASB reactors. Water Res., 94, 146-154. doi:10.1016/j.watres.2016.02.007

8. Sharrad M.O.M., Liu H., Fan M. (2012) Sep. Purif. Technol., 84, 29-34.

9. Das J., Sairam Patra B., Baliarsingh N., Parida K.M. (2007) Calcined Mg-Fe-CO ${ }_{3}$ LDH as an adsorbent for the removal of selenite. J. Colloid Interface Sci., 316, 216-223. doi:10.1016/j.jcis.2007.07.082

10. Tian N., Zhou Z., Tian X., Yang C., Li Y. (2017) Superior capability of $\mathrm{MgAl}_{2} \mathrm{O}_{4}$ for selenite removal from contaminated groundwater during its reconstruction of layered double hydroxides. Sep. Purif. Technol., 176, 66-72. doi:10.1016/j. seppur.2016.11.062

11. MSE Applicaitons Technology Inc. (2001) Selenium treatment/removal alternatives demonstration.

12. Sideris P.J., Nielsen U.G., Gan Z., Grey C.P. (2008) $\mathrm{Mg} / \mathrm{Al}$ ordering in layered double hydroxides revealed by multinuclear NMR spectroscopy. Science, 321, 113-117. doi:10.1126/ science. 1157581
13. Song F., $\mathrm{Hu}$ X. (2014) Exfoliation of layered double hydroxides for enhanced oxygen evolution catalysis. Nat. Commun, 5, 4477. doi:10.1038/ ncomms5477

14. Sajid M., Basheer C. (2016) Layered double hydroxides: emerging sorbent materials for analytical extractions. TrAC - Trends Anal. Chem., 75, 174-182. doi:10.1016/j.trac.2015.06.010

15. Sujata Mandal S., Mayadevi and Bhaskar D., Kulkarni (2009) Adsorption of aqueous selenite [Se(IV)] species on synthetic layered double hydroxide materials. Ind. Eng. Chem. Res., 48, 7893-7898. doi:10.1021/ie900136s

16. Zhang G.S., Qu J.H., Liu H.J., Liu R.P., Li G.T. (2007) Removal mechanism of As(III) by a novel Fe-Mn binary oxide adsorbent: Oxidation and sorption. Environ. Sci. Technol., 41, 4613-4619. doi:10.1021/es063010u

17. Basu D., Das A., Wang D.Y., George J.J., et al. (2016) Fire-safe and environmentally friendly nanocomposites based on layered double hydroxides and ethylene propylene diene elastomer. RSCAdv., 6, 26425-26436. doi:10.1039/ C5RA27444C

18. Gupta A., Balomajumder C. (2015) Biosorptive performance of Escherichia coli supported on Waste tea biomass (WTB) for removal of $\mathrm{Cr}(\mathrm{VI})$ to avoid the contamination of groundwater: $A$ comparative study between biosorption and SBB system. Groundw. Sustain. Dev., 1, 12-22. doi:10.1016/j.gsd.2016.01.001

19. Zhang N., Lin L.S., Gang D. (2008) Adsorptive selenite removal from water using iron-coated GAC adsorbents. Water Res., 42, 3809-3816. doi:10.1016/j.watres.2008.07.025 